\title{
Adsorption Potential of Magnetite Nanoparticles for Copper Removal From Aqueous Solution
}

\author{
Syazana Sulaiman, Raba'ah Syahidah Azis, Ismayadi Ismail, Hasfalina Che Man, Nur Asyikin \\ Ahmad Nazri
}

\begin{abstract}
In this study, the magnetite nanoparticles (MNP) was successfully synthesized from mill scale waste to analyze the removal of $\mathrm{Cu}$ (II) ions from the aqueous solution. The micron-sized magnetite was milled using the high energy ball mills (HEBM with the variation of milling hours 3,5 and 7 to produce nano-sized particles. The MNP were measured by X-Rays Diffraction (XRD), Transmission Electron Microscopy (TEM), Brunauer-Emmett-Teller (BET) and Atomic Absorption Spectroscopy (AAS). Studied parameters are contact time, the initial concentration and particle size. The adsorption kinetics was relatively quick and equilibrium is reached at about 30 minutes. In kinetic studies, the pseudo-second-order model was employed. Langmuir model $\left(R^{2}>0.9987\right)$ corresponded with the adsorption isotherm data of $\mathrm{Cu}$ (II) ions. The adsorption capacity of $\mathrm{Cu}$ (II) ions onto magnetite nanoparticles (MNP) is $11.36 \mathrm{mgg}^{-1}$ at 7 hours milling hours. Pseudo-second-order model and Langmuir isotherm were obeyed with experimental results.
\end{abstract}

Keywords : Magnetite nanoparticles, milling hour, particle size, copper ions, Adsorption kinetics, Isotherm

\section{INTRODUCTION}

Recently, heavy metal pollution has become one of the major global concern to the environment due to rapid industrialization and urbanization [1]. The environmental problem causes severe health issue because they are persistent, non-biodegradable, carcinogenic and toxic in nature [2],[3].

Copper ions are one of the trace elements which is vital for the human body and flora and fauna. $\mathrm{Cu}$ (II) ions generally pass through waste and effluents into water bodies from industrial processes such as manufacturing of plastic, copper polishing, electroplating, and mining activities [4],[5]. Cu (II) ions are one of the necessary but trace elements. Continuous inhalation will increase the risk of lung cancer [6]. Long-term exposure to drinking water containing copper, at even trace level should be strictly prohibited. Besides, high doses of copper can cause anaemia, intestinal irritation, liver, and kidney damage [7]. Due to their toxicity, non-degradability,

Revised Manuscript Received on July 22, 2019

Syazana Sulaiman, Ismayadi Ismail, Nur Asyikin Ahmad Nazri, Institute of Advanced Technology (ITMA), Universiti Putra Malaysia, Malaysia. Email: syazana2104@gmail.com , ismayadi@upm.edu.my, asyikin2750@uitm.edu.my

Raba'ah Syahidah Azis, Department of Physics, Faculty of Science, UPM \& Institute of Advanced Technology (ITMA), UPM. Email: rabaah@upm.edu.my

Hasfalina Che Man, Department of Biological and Agricultural Engineering, Faculty of Engineering, UPM. Email: hasfalina@upm.edu.my easy accumulation of element, the removal of copper from wastewater has attracted much interest worldwide [8].

Nowadays, a few technologies were used for removal of copper from wastewater including ion exchange, precipitation and advanced oxidations. Nevertheless, these techniques are costly. Over the past decades, adsorption separation technology has rapidly evolved and utilized in various industries globally [9]. Adsorption is considered as a simple, attractive, universal, and efficient treatment to remove contaminant within the aqueous phase method for water purification [10]-[12].

There are numerous approaches have been studied for a minimal cost adsorbent for removing heavy metals from wastewater. Due to their unique characteristics of magnetic nanoparticles (MNP) such as superparamagnetic, high adsorption capacities and surface area to volume, it has received significant attention nationwide [13]. Besides, magnetic separation has widely used because of the fast efficient, cost-effective method in water treatment technology [14]. In conjunction with biotechnology, MNP with low chemical inertness, toxicity and biocompatibility indicate enormous potential [15]-[17].

In this work, MNP from the mill scale waste was synthesized. The efficiency of MNP and adsorption kinetics were studied.

\section{EXPERIMENTAI}

\section{A. Preparation of Adsorbents}

The iron oxides were extracted from the mill scale waste product. The mill scale waste was weighed and crushed using conventional milling for 48 hours. The milled powder then was purified by using Magnetic Separation Technique (MST) and Curie Temperature Separation Technique (CTST) as reported by previous literature [18]-[21]. The magnetic materials powder was dried in the oven for 48 hours at $80^{\circ} \mathrm{C}$. The magnetite powder was milled using high energy ball milling (HEBM) using SPEX D8000 dual-drive high energy mills for 3,5 and $7 \mathrm{~h}$ respectively to get the nano-sized particles. 


\section{Adsorption Potential of Magnetite Nanoparticles for Copper Removal From Aqueous Solution}

\section{B. Adsorption Preparation}

The reagents used for synthesis $20 \mathrm{mgL}^{-1}$ of copper stock solutions were prepared by dissolving $1 \mathrm{~L}$ deionized water and copper nitrate in Erlenmeyer flask. The $0.3 \mathrm{~g}$ of MNP was added to $200 \mathrm{~mL}$ of copper solution in the conical flask. The solution was stirred for several minutes before being separated by applying an external magnet. The effect of contact time was analyzed to find the suitable contact time at adsorption is equilibrium. $200 \mathrm{~mL}$ of copper stock solution was treated with $0.3 \mathrm{~g}$ of MNP after a different period. The time of treatments was $0,5,10,15,20,25$, and 30 minutes respectively. Subsequently, 3 different copper ions concentrations; $1,7,11 \mathrm{mgL}^{-1}$ was treated for 30 minutes with $0.3 \mathrm{~g}$ of MNP. All $\mathrm{Cu}$ (II) ions adsorption studies were performed by batch technique.

All batch adsorption were investigated in aqueous solution for an initial $\mathrm{Cu}$ (II) ions concentration of $11 \mathrm{mgL}^{-1}$. First, the effect of contact time was examined to find the suitable contact time at which the nanoparticles are saturated and the adsorption is at equilibrium. The contact time used were 5, 10, 15, 20, 25, 30 minutes. The copper stock solution was treated with $0.3 \mathrm{~g}$ of MNP at room temperature with different periods of contact times. The initial and final concentrations of the sample solutions have been identified by using AAS. The quantity of $\mathrm{Cu}$ (II) ions at equilibrium, $\mathrm{q}_{\mathrm{e}}\left(\mathrm{mgg}^{-1}\right)$ can be determined using Eq. (1):

$q_{e}=\frac{C_{o}-C_{e}}{m} \times V$

where $q_{\mathrm{e}}\left(\mathrm{mgg}^{-1}\right)$ is the adsorption capacity of nanoparticles at time $t . \quad C_{o}$ and $C_{e}$ are the initial and equilibrium concentrations $\left(\mathrm{mgL}^{-1}\right)$ of metals in the solutions. $V$ is the volume of the solution in litres, and $m(\mathrm{~g})$ is the mass of the MNP used.

\section{RESULTS AND DISCUSSION}

\section{A. Structure Characterization}

Fig. 1. displays the XRD pattern of MNP after milled for 3,5 and $7 \mathrm{~h}$. As the milling time increase, the crystalline peak of magnetite is broader. This is due to the particle size decrease and increases the lattice strain. The ball powder jar surface collision causes big stress in the powder particles [22]. Apart from that, as the milling time increases, the peak intensity decreases which lead to more refinement of magnetite particle and reduction in crystallinity with milling.

During the milling process, the powder was collided with the steel balls and milled in the vial. The energy of the collision between the balls and vial transferred to the powders and heating the powder continuously. By prolonging the milling time, the more heat transferred to the powder. Continue collisions in the milling process produce heat generation during the milling process. Hence, the particle size increases as milling time increases [23].

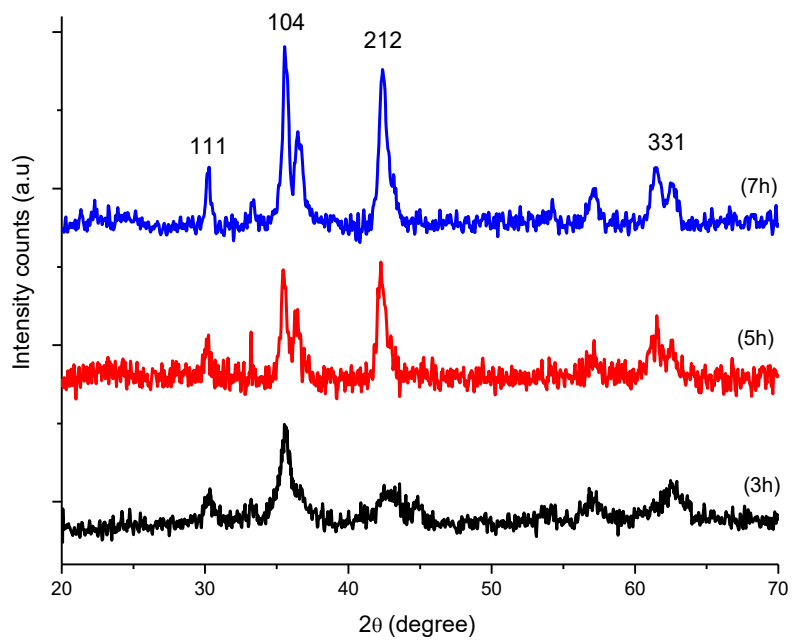

Fig. 1. XRD spectra of MNP milled for 3, 5 and $7 \mathrm{~h}$.

\section{B. Transmission Electron Microscopy (TEM) Analysis}

Fig. 2. (a) shows TEM micrograph of the MNP. The micrograph demonstrates sphere-morphological shape particles that favor the technique of ceramic processing [24]. The TEM micrographs also revealed that the particles were agglomerated even before the TEM measurement through a sonication process was performed. It might be due to the huge surface area of the MNP nanoparticles. These agglomerations also contribute to cold welding and alloying process between the particles. In Fig. 2. (b) the histogram shows the particle size distributions of MNP nanoparticles after $7 \mathrm{~h}$ of milling, nano-sized particles were obtained in the range of $5-10 \mathrm{~nm}$ on average.

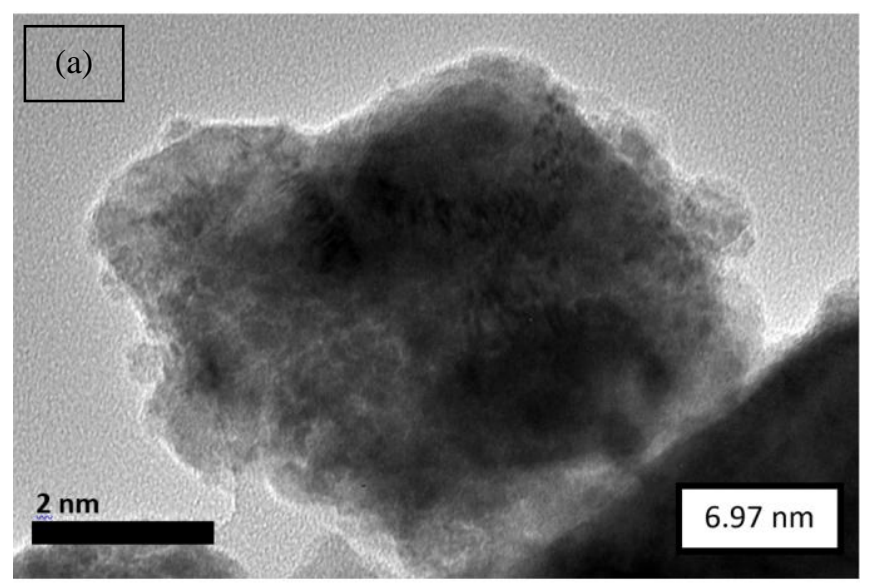




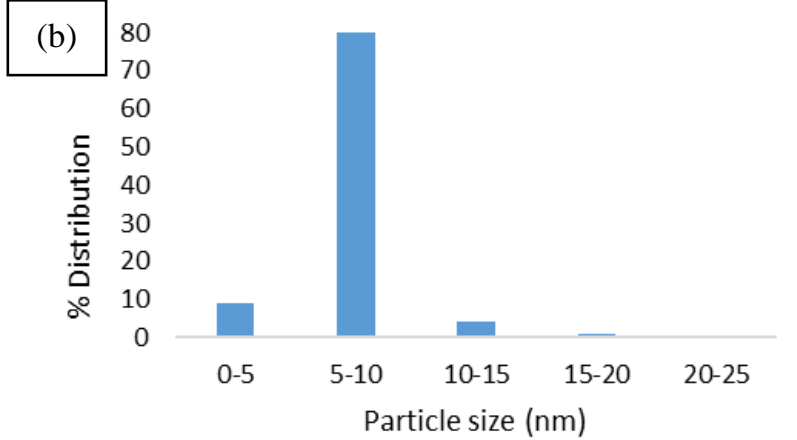

Fig. 2. (a) Transmission electron microscope (TEM) micrograph at $20 \mathrm{~nm}$ and (b) scale bar of particle size distributions of MNP after milling at $7 \mathrm{~h}$.

\section{BET Analysis}

Fig. 3 shows the $\mathrm{N}_{2}$ adsorption and desorption isotherm curve of MNP. Nitrogen adsorption using Brunauer-Emmett-Teller (BET) has been applied to characterize the porous and surface area property of MNP. The nitrogen adsorption-desorption isotherms were determined over the range of relative pressure. The specific surface area observed are 4.9, 6.3 and $5.4 \mathrm{~m}^{2} / \mathrm{g}$ at milling time of 3,5 and $7 \mathrm{~h}$, respectively. The pore size observed are 77.1 , 75.2 and $80.1 \AA$; with the pore volume of $0.009,0.012$ and $0.011 \mathrm{~cm}^{3} / \mathrm{g}$ for of 3,5 and $7 \mathrm{~h}$ milling time, respectively. The BET graph shows the MNP is type III mesoporous with the pore size between 20-500 $\AA$ [25],[26]. Mesoporous offers more available sites for adsorption and plays an important role as a transportation channel that allows adsorbate molecules to diffuse from bulk into adsorbent [27]. This indicates that MNP in $7 \mathrm{~h}$ milling time is a more promising adsorbent. Furthermore, it can be separated quickly from aqueous solution and achieved its regeneration better.

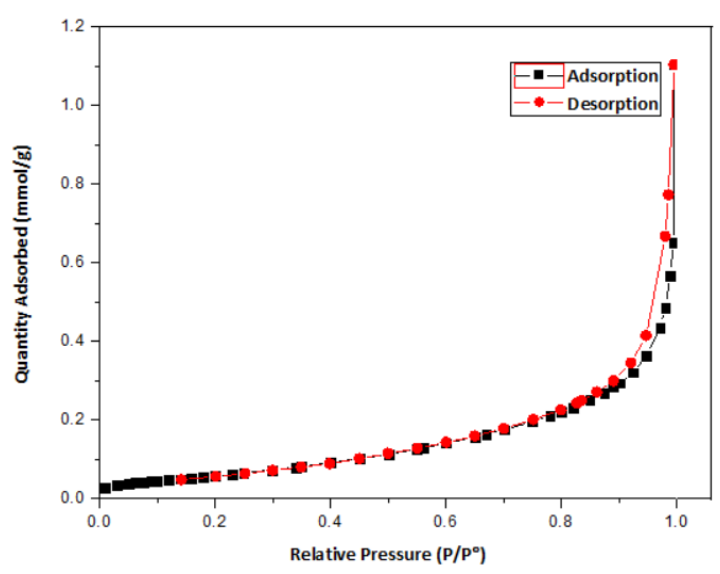

Fig 3. $\mathrm{N}_{2}$ adsorption and desorption isotherm curve of MNP milled for $7 \mathrm{~h}$.

\section{Adsorption Properties}

\section{Effect of Milling Time}

Fig. 4. illustrates the effect of milling time on the percentage removal of $\mathrm{Cu}$ (II) ions. The milling hours are varied at 3,5 and $7 \mathrm{~h}$. As the milling hour increase, the particle size decreases hence the percentage removal increases. The smaller particle size exhibits greater surface area and greater availability of the adsorption site of $\mathrm{Cu}$ (II) ions. The percentage of removal can be deduced by applying Equation 2

$$
\text { Removal } \%=\frac{C_{o}-C_{e}}{C_{o}} \times 100
$$

where $C_{o}$ and $C_{e}\left(\mathrm{mgL}^{-1}\right)$ are the initial and equilibrium concentrations $\left(\mathrm{mgL}^{-1}\right)$ of metals in the solutions.

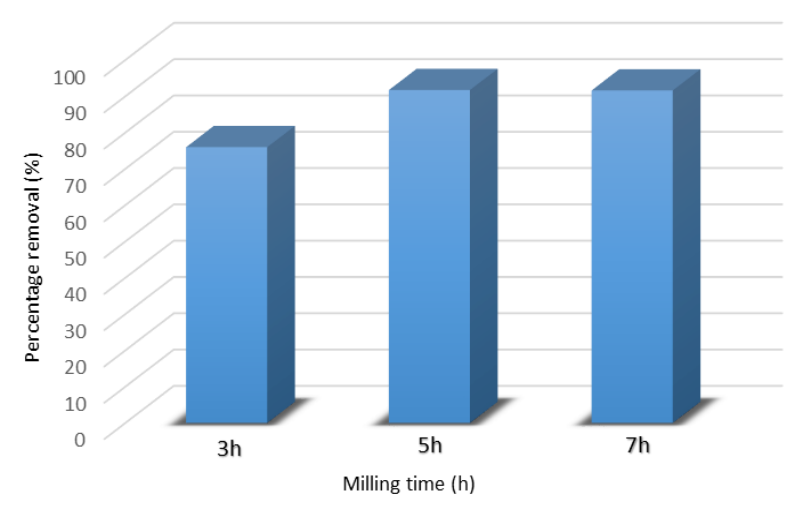

Fig. 4. Removal percentage of $11 \mathrm{mgL}^{-1} \mathrm{Cu}$ (II) ions solution treated at 3,5 and $7 \mathrm{~h}$ milling time for $30 \mathrm{~min}$ contact time.

\section{Effect of Contact Time}

Fig. 5. indicates the effect of contact time on the removal of $\mathrm{Cu}$ (II) ions by MNP. It was revealed that the rate of adsorption for removing $\mathrm{Cu}$ (II) ions is significantly quicker at the beginning of the process. Then slowed down as equilibrium achieved. Consequently, the adsorption takes place faster in the active external sites that are readily available and slowly in the internal sites which are less available [28]. Approximately $93 \%$ of the adsorption capacity was achieved in 30 minutes for 3 milling hours. 


\section{Adsorption Potential of Magnetite Nanoparticles for Copper Removal From Aqueous Solution}

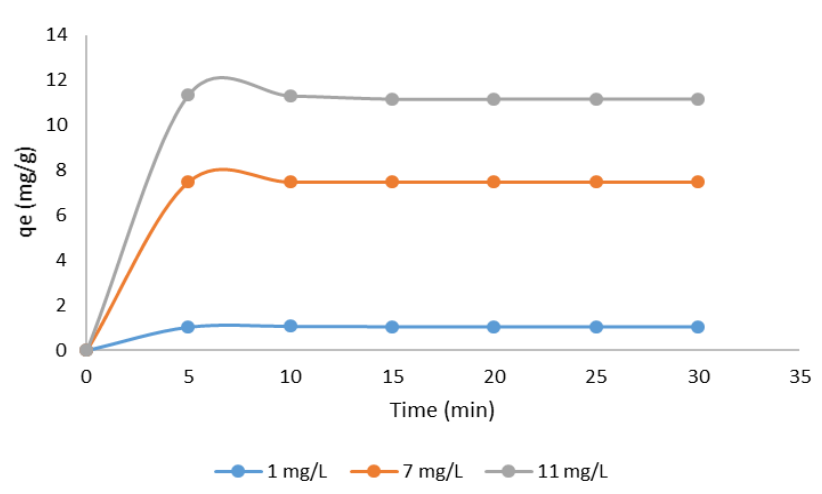

Fig. 5. Effect of contact time of Cu (II) ions onto MNP on the adsorption equilibrium.

\section{Effect of the Initial Concentration of $\mathrm{Cu}(\mathrm{II})$ ions}

The effect of the initial $\mathrm{Cu}$ (II) ions concentration on the adsorption capacity of MNP are $1,7,11 \mathrm{mgL}^{-1}$. The adsorption capacity rises from $1.02 \mathrm{mgg}^{-1}$ to $11.36 \mathrm{mgg}^{-1}$ when the initial metal concentration rises from $1 \mathrm{mgL}^{-1}$ to $11 \mathrm{mgL}^{-1}$ until a steady state is reached in which more metal ion could be discarded [29]. The adsorption capacity vs contact time at different concentration is presented in Fig. 6.

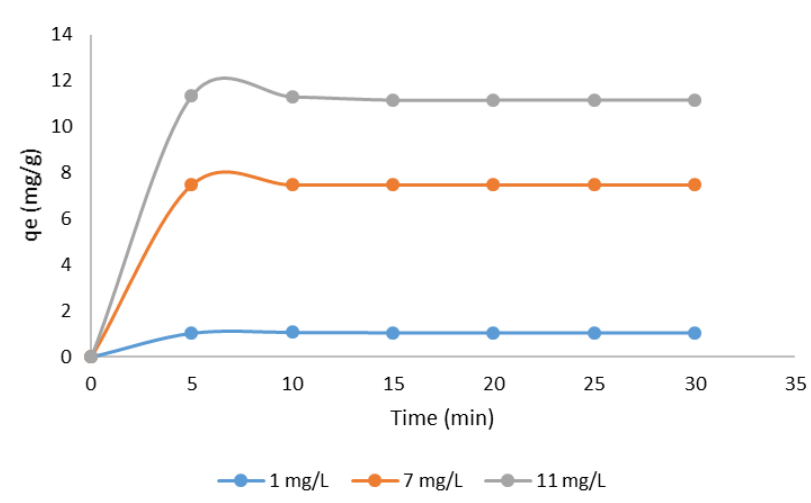

Fig. 6. Effect of initial concentration on the equilibrium adsorption capacity of $\mathrm{Cu}$ (II) ions on the adsorbent.

\section{E. Adsorption Isotherm}

\section{Langmuir Isotherm}

The Langmuir isotherm model rev the presence of monolayer coverage over a homogenous sorbent surface of the sorbate molecules [26]. The linear form of Langmuir adsorption isotherm model and its separation factor $R_{\mathrm{L}}$ as in Eq. (3) and Eq. (4):

$$
\begin{aligned}
& \frac{c_{e}}{q_{e}}=\frac{1}{q_{\max } b}+\frac{c_{e}}{q_{\max }} \\
& R_{L}=\frac{1}{1+b C_{i}}
\end{aligned}
$$

where $q_{\mathrm{e}}\left(\mathrm{mgg}^{-1}\right)$ is the equilibrium adsorbed, $C_{\mathrm{e}}\left(\mathrm{mgL}^{-1}\right)$ is the adsorbate concentration at equilibrium, $q_{\max }\left(\mathrm{mgg}^{-1}\right)$ is the maximum monolayer absorbed, $b\left(\mathrm{Lmg}^{-1}\right)$ represent the adsorption-related Langmuir constant. Langmuir constant $q_{\max }$ and $b$ were computed from the slope and intercept of the linear plot of $C_{\mathrm{e}} / q_{\mathrm{e}}$ versus $C_{e}$.

The percentage of $\mathrm{Cu}$ (II) ions removal was investigated by optimized adsorbent dosage parameters of $1 \mathrm{~g} / \mathrm{L}$, the particle size of $6.97 \mathrm{~nm}, \mathrm{pH}$ of 5, and contact time of 30 minutes at a different concentration. The experimental results are obeyed to the Langmuir isotherm model as illustrated in Fig. 7, the regression $R^{2}$ obtained for temperature $301 \mathrm{~K}$ is 0.9987 .

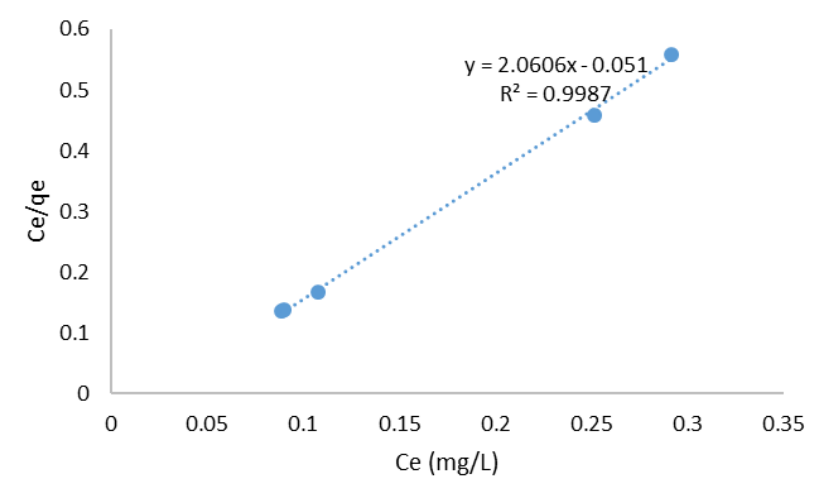

Fig. 7. Langmuir isotherm of $\mathrm{Cu}$ (II) ions adsorption onto MNP. Dashed line corresponds to the best linear fit to the experimental results.

\section{F. Kinetic study}

Fig. 8 shows the pseudo-second-order of the kinetic study. The calculated $q_{\mathrm{e}}$ values are in agreement with the theoretical values and the graph shows good linearity with $R^{2}$ above 0.772. Therefore, the adsorption kinetics of MNP obeys the pseudo-second-order model. The adsorption kinetic represented involving the donation or ions exchange between adsorbate and adsorbent.

The pseudo-second-order is described as in Eq. (5) [27]-[30].

$$
\frac{t}{q_{t}}=\frac{1}{k_{2} q_{e}^{2}}+\frac{t}{q_{e}}
$$

where $q_{\mathrm{t}}$ and $q_{\mathrm{e}}$ are the adsorption capacity $\left(\mathrm{mgg}^{-1}\right)$ at any $t$ (min) and at the equilibrium. $k_{2}$ is the adsorption rate constant (g/mgh). 


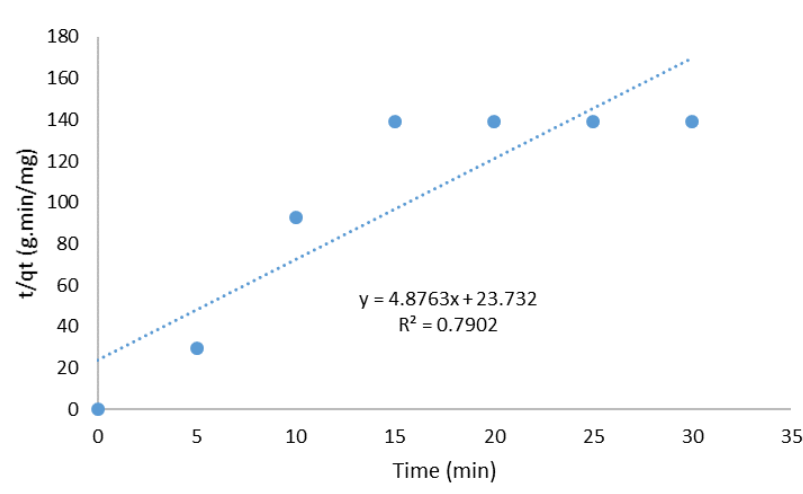

Fig. 8. Sorption kinetics of Pseudo-second-order of $\mathrm{Cu}$ (II) ions species at $11 \mathrm{mgL}^{-1}$ onto MNP.

\section{CONCLUSION}

In this study, the high content of iron magnetite in mill scale waste indicated significant advantages for removing $\mathrm{Cu}$ (II) ions. The best milling hour of adsorption capacity is $7 \mathrm{~h}$ and the maximum adsorption capacity was $11.36 \mathrm{mgg}^{-1}$. Therefore, the adsorption behaviour was well fitted with the Langmuir isotherm model. The results also evidenced the magnetite is an excellent adsorbent for treating the $\mathrm{Cu}$ (II) ions. Further study probably involving several metal ions and real wastewater application to make MNP are more feasible for industrial wastewater treatment.

\section{ACKNOWLEDGEMENT}

The authors are thankful for grants from Universiti Putra Malaysia (UPM), Inisiatif Putra Berkumpulan (IPB) GPB/2017/9541600, GP/2018/ 9628400 and IPS Putra research grant, UPM/ 800-3/3/1/(GP- IPS/2017/9533300, GP-IPS/2017/9539100. The authors also thanks to the Fundamental Research Grant Scheme (FRGS) and Long-term Research Grant Scheme [LRGS/ B-U/ 2013/ UPNM/ Defence \& Security-P2], Malaysian Ministry of Higher Education (MOHE).

\section{REFERENCES}

1. Ngah, W. W., \& Hanafiah, M. A. K. M, "Removal of heavy metal ions from wastewater by chemically modified plant wastes as adsorbents: a review" Bioresource technology, vol. 99, no. 10, 2008, pp. 3935-3948.

2. Bailey, S. E., Olin, T. J., Bricka, R. M., \& Adrian, D. D., “A review of potentially low-cost sorbents for heavy metals", Water research, vol. 33, no. 11,1999 , pp. 2469-2479.

3. Gautam, R. K., Sharma, S. K., Mahiya, S., \& Chattopadhyaya, M. C., "Contamination of heavy metals in aquatic media: transport, toxicity, and technologies for remediation" Heavy metals in water: Presence, removal and safety, 2014, pp. 1-24.

4. Ofomaja, A. E., "Equilibrium studies of copper ion adsorption onto palm kernel fibre," Journal of environmental management, vol. 91, no. 7, 2010, pp. 1491-1499.

5. Futalan, C. M., Kan, C. C., Dalida, M. L., Hsien, K. J., Pascua, C., \& Wan, M. W., "Comparative and competitive adsorption of copper, lead, and nickel using chitosan immobilized on bentonite," Carbohydrate Polymers, vol.83, no. 2, 2011, pp. 528-536.

6. Zhang, C., Zhang, F., Diao, H., Gao, M. C., Tang, Z., Poplawsky, J. D., \& Liaw, P. K., "Understanding the phase stability of Al-Co-Cr-Fe-Ni high entropy alloys," Materials \& Design, vol. 109, 2016, pp. 425-433.

7. Gupta, H., \& Gogate, P. R., " Intensified removal of copper from waste water using activated watermelon based biosorbent in the presence of ultrasound," Ultrasonics Sonochemistry, vol. 30, 2016, pp. 113-122.9.

8. Cai, X., Lee, A., Ji, Z., 8. Huang, C., Chang, C. H., Wang, X., \& Li, R., "Reduction of pulmonary toxicity of metal oxide nanoparticles by phosphonate-based surface passivation," Particle and fibre toxicology, vol. 14, no. 1, 2017, pp.13.

9. Dąbrowski, A., "Adsorption - from theory to practice," Advances in colloid and interface science, vol. 93, no. 1-3, 2001, pp.135-224.

10. Gupta, V. K., Carrott, P. J. M., Ribeiro Carrott, M. M. L., \& Suhas., "Low-cost adsorbents: growing approach to wastewater treatment-a review," Critical Reviews in Environmental Science and Technology, vol. 39 , no. 10 , pp. $783-842$.

11. Ali, I., \& Gupta, V. K., "Advances in water treatment by adsorption technology," Nature protocols, vo. 1, no. 6, 2006, pp. 2661.

12. Sulaymon, A. H., Mohammed, A. A., \& Al-Musawi, T. J., "Comparative study of removal of cadmium (II) and chromium (III) ions from aqueous solution using low-cost biosorbent," International Journal of Chemical Reactor Engineering, vol. 12, no. 1, 2014, pp. 477-486.

13. Kefeni, K. K., Mamba, B. B., \& Msagati, T. A., "Application of spinel ferrite nanoparticles in water and wastewater treatment: a review," Separation and Purification Technology, vol. 188, 2017, pp. 399-422.

14. R. S. Azis, M. M. Syazwan, N. M. M. Shahrani, A. N. Hapishah, R. Nazlan, F. M. Idris, I. Ismail, M. M. M. Zulkimi, I. R. Ibrahim, "Influence of sintering temperature on the structural, electrical and microwave properties of yttrium iron garnet (YIG)," Journal of Materials Science: Materials in Electronics, vol. 29, no. 10, 2018, pp. 8390-8401

15. Huang SH, Liao MH, Chen DH, "Direct binding and characterization of lipase onto magnetic nanoparticles," Biotechnol Prog, vol. 19, no. 3, 2003, pp.1095-100.

16. Roco MC, "Nanotechnology: convergence with modern biology and medicine," Curr Op in Biotechnol, vol. 14, no. 3, pp. 337-46.

17. Gupta AK, Gupta M., "Synthesis and surface engineering of iron oxide nanoparticles forbiomedical applications," Biomaterials, vol. 26, no. 18 , 2005, pp. 3995-4021.

18. R.S.Azis, M. Hashim, N.M.Saiden, N.Daud and N.M.M.Shahrani, "Study The Iron Environments Of The Steel Waste Product And Its Possible Potential Applications In Ferrites," Advanced Materials Research, vol. 1109, 2015, pp. 295-299.

19. R. S. Azis, M. M. Syazwan, N. M. M. Shahrani, A. N. Hapishah, R. Nazlan, F. M. Idris, I. Ismail, M. M. M. Zulkimi, I. R. Ibrahim, "Influence of sintering temperature on the structural, electrical and microwave properties of yttrium iron garnet (YIG)," Journal of Materials Science: Materials in Electronics, vol. 29, no. 10, 2018, pp. 8390-8401

20. Daud, N., Azis, R. S.,Hashim, M., Matori, K. A., Hassan, J., Saiden, N. M., Shahrani, N. M. M., "Preparation and Characterization of $\mathrm{Sr}_{1-\mathrm{x}} \mathrm{Nd}_{\mathrm{x}} \mathrm{Fe}_{12} \mathrm{O}_{19}$ Derived From SteelWaste Product via Mechanical Alloying," Materials Science Forum , vol. 846, 2015, pp. 403-409.

21. Azis, R. S., Hashim, M., Yahya, N., Saiden, N. M., "A Study of Sintering Temperatures Variation on Microstructure Developments of Strontium Hexaferrite Millscale-Derived," Journal of Applied Sciences, vol. 2, 2002, pp. 1092-1095.

22. Agarwal, A., \& Bhushan, M., "Synthesis of Iron Oxide Pigment by Planetary Milling," in Doctoral dissertation, 2015.

23. R. S. Azis, Hashim, M., N. Yahya, N.M.Saiden, Z. Hari, "Effect of milling time on the particle size and microstructure of millscale derived $\mathrm{BaFe}_{12} \mathrm{O}_{19}$ ", in Solid State Ionics: Trends in the New Millennium, 2002, pp. 575-582.

24. Klobes, P., \& Munro, R. G., "Porosity and specific surface area measurements for solid materials," 2006.

25. Romero-Cano, L. A., García-Rosero, H., Gonzalez-Gutierrez, L. V., Baldenegro-Pérez, L. A., \& Carrasco-Marín, F., "Functionalized adsorbents prepared from fruit peels: Equilibrium, kinetic and thermodynamic studies for copper adsorption in aqueous solution," Journal of cleaner production, vol. 162, 2017, pp. 195-204.

26. de Melo, N. H., de Oliveira Ferreira, M. E., Neto, E. M. S., Martins, P. R., \& Ostroski, I. C., "Evaluation of the adsorption process using activated bone char functionalized with magnetite nanoparticles," Environmental nanotechnology, monitoring \& management, vol. 10, 2018, pp. 427-434.

27. Do, D. D., "Adsorption analysis: equilibria and kinetics," London: Imperial college press, vol. 2, 1998, pp. 1-18.

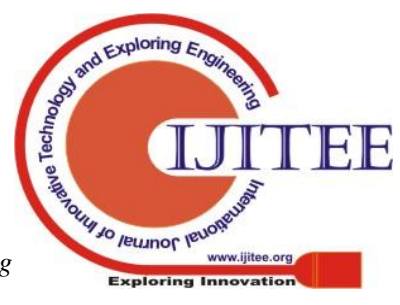




\section{Adsorption Potential of Magnetite Nanoparticles for Copper Removal From Aqueous Solution}

28. Achak, M., Hafidi, A., Ouazzani, N., Sayadi, S., \& Mandi, L., "Low cost biosorbent "banana peel" for the removal of phenolic compounds from olive mill wastewater: Kinetic and equilibrium studies," Journal of hazardous materials, vol. 166, no. 1, 2009, pp. 117-125.

29. Uheida, A., Iglesias, M., Fontàs, C., Hidalgo, M., Salvadó, V., Zhang, Y., \& Muhammed, M., "Sorption of palladium (II), rhodium (III), and platinum (IV) on Fe3O4 nanoparticles," Journal of colloid and interface science, vol. 301, no. 2, 2006, pp. 402-408.

30. Nassar, N. N., " Rapid removal and recovery of $\mathrm{Pb}$ (II) from wastewater by magnetic nanoadsorbents," Journal of hazardous materials, vol. 184, no. $1-3,2010$, pp. $538-546$.

\section{AUTHORS PROFILE}

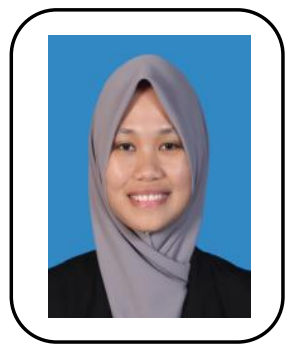

Syazana Sulaiman, Master student of Universiti Putra Malaysia. She is a student at the Material Synthesis and Characterization Laboratory (MSCL), Institute of Advanced Materials (ITMA), UPM. Her research field is magnetic and nanomaterials in wastewater treatment.

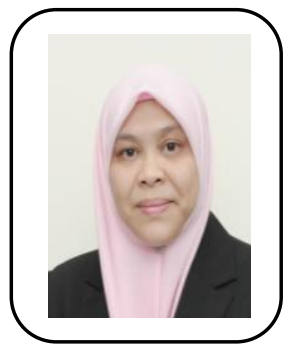

Raba'ah Syahidah Azis (Ph.D.) is an Associate Professor at the Department of Physics, Universiti Putra Malaysia. She is an Associate Researcher at the Material Synthesis and Characterization Laboratory (MSCL), Institute of Advanced Materials (ITMA), UPM. She is also an Auditor of Malaysian Solid State Science and Technology (MASS). Her research interest in material synthesis and characterization specialized in magnetic materials, nanomaterial, ferrites, magnetic materials used in the wastewater treatment process (WWTP) and radar adsorbing materials (RAM).

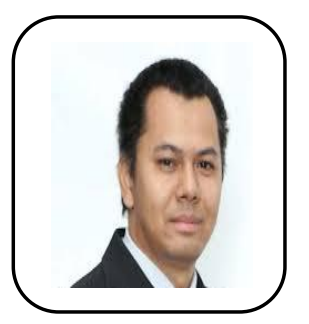

Ismayadi Ismail (Ph.D.), is a Researcher Institute of Advanced Materials (ITMA), Universiti Putra Malaysia. He is also an active member of Malaysian Solid State Science and Technology (MASS). His research skills and expertise are material characterizations, materials, nanomaterial, and microstructure.

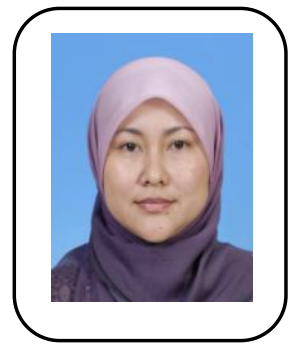

Hasfalina Che Man (Ph.D.) is an Associate Professor at the Department of Biological and Agricultural Engineering, Faculty of Engineering, UPM. She is also a Chartered Engineer of IChemE ((Institution of Chemical Engineers). Her research interest is bio-environmental engineering, environmental engineering, wastewater treatment, and agriculture waste management.

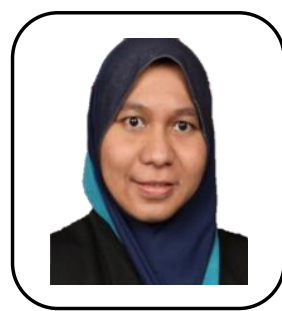

Nur Asyikin Ahmad Nazri, is a Ph.D. of Materials Synthesis and Characterization Laboratory (MSCL) at the Institute of Advanced Technology (ITMA), Universiti Putra Malaysia (UPM). Her skills and interest are nanomaterials and magnetic materials. 